\title{
Bant Çentik Karakteristiği Gösteren Ultra Geniş Bant Mikroşerit Anten Tasarımları Üzerine Bir İnceleme
}

\author{
Gürtay Sezay Gürsoy ${ }^{1 *}$, Sena Esen Bayer Keskin ${ }^{2}$ \\ 1* İstanbul Arel Üniversitesi, Mühendislik-Mimarlık Fakültesi, Elektrik-Elektronik Mühendisliği Bölümü, İstanbul, Türkiye, (ORCID: 0000-0003-4291-0101), \\ gurtaysezaygursoy@arel.edu.tr \\ ${ }^{2}$ Kırklareli Üniversitesi, Mühendislik Fakültesi, Elektrik-Elektronik Mühendisliği Bölümü, Kırklareli, Türkiye (ORCID: 0000-0001-8309-3393), \\ senaesenbayer@gmail.com
}

(2nd International Conference on Access to Recent Advances in Engineering and Digitalization (ARACONF)-10-12 March 2021)

(DOI: $10.31590 /$ ejosat.903121)

\begin{abstract}
ATIF/REFERENCE: Gürsoy, G.S., Bayer Keskin, S.E. (2021). Bant Çentik Karakteristiği Gösteren Ultra Geniş Bant Mikroşerit Anten Tasarımları Üzerine Bir İnceleme. Avrupa Bilim ve Teknoloji Dergisi, (24), 314-320.
\end{abstract}

$\ddot{O} \mathbf{z}$

Ultra Geniş Bant (UGB) teknolojisi özellikle kısa mesafeli iletişimlerde, çok düşük enerji seviyelerinde çalışabilen bir radyo teknolojisidir. Bu teknoloji sayesinde, dijital verilerin oldukça düşük enerji seviyelerinde ve yüksek veri hızlarında geniş bir frekans spektrumu üzerinden iletilmesi sağlanmaktadır. UGB teknolojisinin kablosuz sistemlerde kullanımı için 3.1-10.6 GHz frekans bandı, Federal İletişim Komisyonu (FİK) tarafından tanımlanmıştır ve bu frekans aralığında; WiMAX (3.3-3.7 GHz), WLAN (5.15-5.85 GHz), C-bant (3.8-4.2 GHz) ve X-bant (7.25-7.75 ve 7.9-8.4 GHz) gibi birçok dar bantlı iletişim sistemi yer almaktadır. UGB teknolojisinin, dijital iç mekân ve ev ağları uygulamaları için veri iletiminin düşük maliyetli ve yüksek hızlı olarak gerçekleştirmesi gibi avantajlarının yanında, 3.1-10.6 GHz frekans bandında yer alan dar bantlı iletişim sistemlerinden kaynaklanan elektromanyetik parazitlenme gibi bir dezavantajı bulunmaktadır. İletişim kalitesini arttırmak ve istenmeyen sinyalleri engellemek için mikrodalga filtreler kullanılabilir ancak bu yöntem sistemin maliyetini ve hacmini arttırdığı gibi kayıplara da neden olmaktadır. Bu nedenle, literatürde mevcut bantlardan kaynaklanan potansiyel parazitlenmeyi önlemek için bant reddetme özelliklerine sahip UGB antenlerinin tasarımı üzerine çok sayıda araştırma bulunmaktadır. Literatürdeki çalışmalar incelendiğinde, parazit sorunlarını önlemek için farklı yaklaşımlar kullanan, bant çentik karakteristiği gösteren birçok UGB anten geliştirildiği görülmüştür. Bu çalışmalarda; yama ve toprak düzleminde yarıklar kullanma, besleme hattı veya toprak düzleminde saplamalar kullanma, parazitik şerit kullanma, Elektromanyetik Bant Boşluğu (EBB) yapıları kullanma ve Yarı Halka Rezonatör (YHR) kullanma gibi tekniklerin tercih edildiği ve bu teknikler sayesinde de WiMAX, WLAN, X-bant ve C-bant frekans bantlarında bant çentik karakteristiği gösteren mikroşerit anten tasarlandığı gözlenmiştir. Bu bildiri kapsamında, UGB bandında çalışan ve bant çentik karakteristiği gösteren, literatürde yer almış mikroşerit anten çalışmalarının derlemesi sunulmuştur. Yapılan derleme sonucunda, kullanılan çeşitli teknikler sayesinde hem dar bantlı iletişim sistemlerinde bant çentik karakteristiği sağlandığı, hem de kazanç, bant genişliği ve geri dönüş kaygı gibi performans parametrelerinde de farklı sonuçlar elde edildiği görülmüştür.

\section{Ultra Wideband Microstrip Antenna Designs Showing Band-Notch Characteristic: A Review}

\begin{abstract}
Ultra Wide Band (UWB) is a radio technology that can operate at a very low energy level especially in short distance communication. By means of this technology, digital data are transmitted through a wide frequency spectrum in very low energy and high data speed.
\end{abstract}

* Sorumlu Yazar: gurtaysezaygursoy@arel.edu.tr 
3.1-10.6 GHz frequency band was identified in order that uses UWB technology in wireless systems by Federal Communication Commission (FCC) and there are many narrowband communication systems like WiMAX (3.3-3.7 GHz), WLAN (5.15-5.85 GHz), Cband (3.8-4.2 GHz) ve X-band (7.25-7.75 and 7.9-8.4 GHz) in this frequency band. Apart from the advantages of UWB systems like realise low cost and very speed digital indoor and home network applications has a disadvantage known as electromagnetic interference due to narrowband communication systems that situate in the 3.1-10.6 GHz frequency band. In order to increase the communication quality, filters can be used, however, this method increases the cost and size of the system. Also, it causes losses in communication. Therefore, there is a lot of research in the literature about UWB antenna designs that have a band-notched characteristic in order that block potential interference stemming from a narrowband communication system. According to works in the literature, in order to achieve band-notched characteristic, researchers usually have prefered like technics using the slot on the patch or ground plane, parasitic strip, Electromagnetic Band Gap (EBG) structure, stub and Split Ring Resonator (SRR) structure. In this letter, it is presented the review of microstrip antennas that operate in the UWB frequency band (3.1-10.6 GHz) and show band-notched characteristic in the narrowband communication system. As a result, by means of using these different technics in the literature, both band-notched characteristic in the different narrowband frequency band like WiMAX, WLAN, X-band, C-band and different results has been achieved in the performance parameters like gain, bandwidth, return loss.

Keywords: UWB, band-notched, WiMAX, WLAN, X-band.

\section{Giriş}

Kompakt yapıya sahip, düşük maliyetli, kolay üretilebilen ve birçok cihaza kolay uyarlanabilir antenlere; kablosuz haberleşme, uydu haberleşmesi, havacılık gibi alanlarda duyulan ihtiyaç giderek artmaktadır. Bu ihtiyacın giderilmesi için de son yıllarda kullanımı bir hayli yaygınlaşan ve birçok avantaja sahip mikroşerit antenler tercih edilmektedir. Mikroşerit antenler düşük profilli olup düzlemsel ve düzlemsel olmayan yüzeylere kolayca uyum sağlamaktadır (Balanis, C. A., 2016).

Mikroşerit anten tasarımında sıklıkla tercih edilen yöntemlerden biri de UGB teknolojisinin kullanılmasıdır. Bu sistemler, düşük maliyetli ve yüksek hızlı dijital iç mekân ve ev ağları uygulamalarında oldukça avantaj sağlamaktadır. FİK, Şubat 2002'de UGB sistemleri için ilk emisyon limitleri bildirisini yayınlayarak bu sistemlerin ticarileşmesini sağlamıştır (FİK Bildirisi, 2002). Bu bildiriye göre, 3.1-10.6 GHz frekans bandı UGB sistemleri için tanımlanmıştır. UGB teknolojisinin geniş bant genişliğine sahip olması; düşük güç tüketimi, yüksek veri hızı, düşük maliyetli uygulama, dar bant sistemleriyle birlikte var olma gibi çeşitli avantajları beraberinde getirmektedir (Ian Oppermann ve ark, 2004).

UGB teknolojisinin bu avantajlarının dışında, 3.1-10.6 GHz frekans bandında bulunan; WiMAX (3.3-3.7 GHz), WLAN (5.155.85 GHz), C-bant (3.8-4.2 GHz), X-bant (7.25-7.75 ve 7.9-8.4 $\mathrm{GHz}$ ) frekans bantlarının yol açtığı elektromanyetik parazitlenme gibi bir dezavantajı bulunmaktadır. Literatür incelendiğinde UGB teknolojisinin avantajlarından daha fazla yararlanmak için bu frekans bantlarında bant çentik karakteristiği gösteren mikroşerit anten tasarımlarına ihtiyaç duyulduğu görülmüştür. Bir sonraki başlık altında da bu tasarımların detaylıca incelemesi sunulmuştur.

\section{Materyal ve Metot}

Literatür incelendiğinde, tasarlanan UGB antenlerinin bant çentik karakteristiği göstermesi için pek çok farklı teknik kullanıldığı görülmektedir. Bunlar; yama ve toprak düzleminde yarıklar kullanma, besleme hattı veya toprak düzleminde saplamalar kullanma, parazitik şerit kullanma, EBB yapıları kullanma ve YHR kullanma olarak sıralanabilir.

\subsection{Literatürde Kullanılan Yöntemler}

\subsubsection{Yarık Kullanma}

Literatürde, UGB teknolojisinde dar bantlı sistemlerden kaynaklanan parazitlenmelerin önüne geçmek için uygulanan yöntemlerden biri antenin yama ve toprak düzleminde yarıklar oluşturulmasıdır. Bu yönteme örnek olarak dairesel bir yama üzerinde oluşturulan U şekilli yarığa sahip anten geometrisi Şekil 1 'de gösterilmiştir. Yarıklar içeren çalışmalar incelendiğinde, yama ve/veya toprak düzlemine yerleştirilen yarıkların boyutu, istenen çentik frekansının yaklaşık olarak yarı dalga boyu uzunluğuna sahip olduğunda bant çentik işlemi gerçekleştiği gözlenmiştir.

Husham J. Mohammed ve ark. dairesel yama üzerine Cşekilli ve ark-şekilli yarık kullanarak WiMAX, WLAN ve C-bant frekans bantlarında, bant çentik karakteristiği gösteren UGB anten tasarlamıştır. Antende alt katman malzemesi olarak FR-4, besleme yöntemi olarak da mikroşerit hat besleme yöntemi tercih edilmiştir. C-şekilli ve ark-şekilli yarıklar ile bant çentik karakteristiği elde edilmiş, ayrıca Parçacık Sürüsü Optimizasyonu (PSO) ve Ateşböceği Algoritması (AA) kullanılarak anten parametrelerinin optimizasyonu sağlanmıştır. Elde edilen anten; 28 x $30 \mathrm{~mm}^{2}$ boyuta ve 2.7 ile $10.6 \mathrm{GHz}$ arası çalışma frekansına sahiptir (Husham J. Mohammed ve ark., 2016).

Neelaveni Ammal Murugan ve ark. U şekilli yarık ile WiMAX, WLAN ve X-bant frekans bantlarında, bant çentik karakteristiği gösteren UGB anten tasarlamışlardır. Antende alt katman malzemesi olarak FR-4, besleme yöntemi olarak da mikroşerit hat beslemesi tercih edilmiştir. Yama ortasındaki U şekilli yarık WiMAX bandını, yama düzleminin yan kısmında bulunan yarık X-bandını, yama düzleminin alt kısmındaki yarık ise WLAN bandını durdurmuştur. Elde edilen anten; 30 x $28 \mathrm{~mm}^{2}$ boyuta ve 2.14-4.67 dB arası kazanca sahiptir (Neelaveni Ammal Murugan ve ark., 2016).

Hari Shankar Mewara ve ark. Y şekilli yama üzerine, C ve U şekilli yarık yerleştirerek WiMAX, WLAN, X-bant, ITU-8 (7.9$8.5 \mathrm{GHz})$ ve RN (9-10 GHz) frekans bantlarında, bant çentik karakteristiği gösteren UGB anten tasarlamışlardır. Antende alt katman malzemesi olarak FR-4, besleme yöntemi olarak da mikroşerit hat beslemesi tercih edilmiştir. C ve U şekilli yarıklar yama üzerine yerleştirilmesiyle WiMAX ve WLAN band, yarıkların toprak düzlemine yerleştirilmesiyle X-bant, ITU-8 ve $\mathrm{RN}$ frekans bantlarında filtrelenme sağlanmıştır. Elde edilen 
anten; $36 \times 38 \mathrm{~mm}^{2}$ boyuta, 2.86 ile $13.3 \mathrm{GHz}$ arası çalışma frekansına ve 2.2 ile $4.5 \mathrm{dBi}$ arası kazanca sahiptir (Hari Shankar Mewara ve ark., 2017).

H. Hosseini ve ark. tarafından L șekilli yarık kullanılarak WiMAX, WLAN, ve X-bant frekans bantlarında, bant çentik karakteristiği gösteren UGB anten tasarlanmıştır. Antende alt katman malzemesi olarak Rogers 4003, besleme yöntemi olarak da düzlemsel dalga kılavuzu besleme yöntemi tercih edilmiştir. L şekilli yarıkların boyutu, çeyrek dalga boyu olarak belirlenmiş ve bu yarığın, anten üzerindeki konumuna ve simetrisine göre bant çentik işlemi sağlanmıştır. Elde edilen anten 21 x $14 \mathrm{~mm}^{2}$ boyuta, 3 ile $12 \mathrm{GHz}$ arası çalışma frekansına ve $2.3 \mathrm{dBi}$ kazanca sahiptir (H. Hosseini ve ark., 2018).

Literatürdeki diğer çalışmalar da incelendiğinde görülmüştür ki anten tasarımında yarık kullanarak bant çentik karakteristiği elde etme yöntemi en basit ve alışagelmiş yöntemdir.

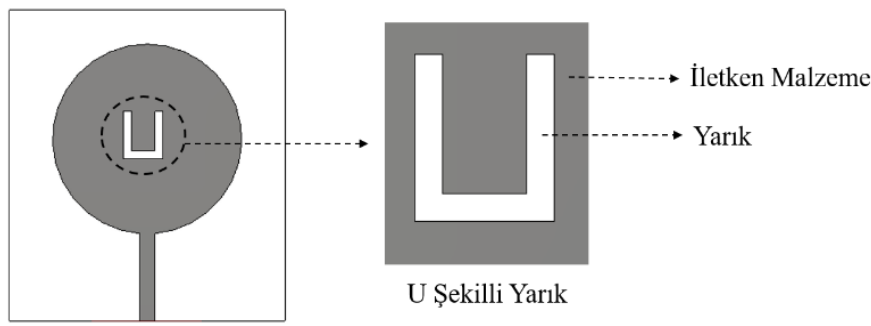
Şekil 1. U Şekilli Yarık Kullanılarak Oluşturulan Anten
Geometrisi

\subsubsection{Saplama Modülü Kullanma}

UGB antenlerde bant çentik karakteristiği sağlamak için literatürde tercih edilen bir başka teknik de saplamaların kullanılmasıdır. Saplamalar, yarık kullanımına benzer şekilde antenin; yama, toprak ve besleme hattına yerleştirilebilir. Yazarların elde ettikleri bulgulara göre açık devre olarak düşünülen saplamaların uzunluğu, çeyrek dalga boyu olarak seçildiğinde bant çentik işlemi gerçekleşmektedir.

Wen Jiang ve ark. yaptıkları tasarımda T ve U şekilli saplama kullanarak WiMAX ve WLAN frekans bantlarında, bant çentik karakteristiği gösteren UGB anten tasarlamıştır. Antende alt katman malzemesi olarak Rogers4003, besleme yöntemi olarak da mikroşerit hat beslemesi tercih edilmiştir. T şekilli saplama yamanın ortasına, U şekilli saplama ise besleme hattı yanına yerleştirilmesiyle bant çentik karakteristiği elde edilmiştir. Elde edilen anten, 2.8 ile $11 \mathrm{GHz}$ arası çalışma frekansına sahiptir (Wen Jiang ve ark., 2012).

Junhui Wang ve ark. ikizkenar yamuk şeklindeki yama düzlemine, T ve U şekilli saplama modülleri ekleyerek WiMAX ve WLAN frekans bantlarında bant çentik karakteristiği gösteren UGB anten tasarlamıştır. Antende alt katman malzemesi olarak FR-4, besleme yöntemi olarak da mikroşerit hat beslemesi tercih edilmiştir. Yama düzleminde tercih edilen U şekilli saplama WiMAX, T şekilli saplama ise WLAN bandının filtrelenmesi için kullanılmıştır. Elde edilen anten; 26 x $27.3 \mathrm{~mm}^{2}$ boyuta ve 3 ile $11 \mathrm{GHz}$ arası çalışma frekansına sahiptir (Junhui Wang ve ark., 2013).

\subsubsection{Parazitik Şerit Kullanma}

Bant çentik işlemi için uygulanan bir başka teknik ise anten yayılım elemanı olan yamada veya toprak düzleminde parazitik şerit elemanı kullanılmasıdır. Bu tekniğe parazitik şerit ismi verilmesinin nedeni ise parazitik şerit elemanının, yayılım elemanı ile doğrudan beslenmemesinden kaynaklanmaktadır. Parazitik şeritler, istenen bant çentik frekansında rezonansa girerek akım dağılımını bozar ve antenin o frekans bandında çalışmamasını sağlar.

Ke Zhang ve ark. dairesel yamadaki simetrik yarıklar ile parazitik şerit oluşturarak WLAN frekans bandında bant çentik karakteristiği gösteren UGB anten tasarlamıştır. Antende alt katman malzemesi olarak Wangling F4Bm-2, besleme yöntemi olarak da mikroşerit hat besleme yöntemi tercih edilmiştir. Ayrıca yarıkların yama merkezine uzaklığının parametrik analizi yapılarak bant çentik karakteristiği açısından optimum değer belirlenmiştir. Elde edilen anten; $37 \mathrm{x} 47 \mathrm{~mm}^{2}$ boyuta ve 2.8 ile $13.5 \mathrm{GHz}$ arası çalışma frekansına sahiptir (Ke Zhang ve ark., 2010).

Xianglong Liu ve ark. toprak düzlemine, dairesel yarık ve parazitik şerit ekleme yöntemi ile WiMAX ve WLAN frekans bantlarında, bant çentik karakteristiği gösteren UGB anten tasarlamıştır. Antende alt katman malzemesi olarak FR-4, besleme yöntemi olarak da düzlemsel dalga kılavuzu yöntemi tercih edilmiştir. Antenin arka yüzeyinde yer alan L şekilli parazitik şerit ile anten, WiMAX ve WLAN bandında bant çentik karakteristiği göstermiştir. Elde edilen anten; $40 \times 30 \mathrm{~mm}^{2}$ boyuta ve $7.3 \mathrm{dBi}$ kazanca sahiptir (Xianglong Liu ve ark., 2013).

Parazitik şerit ekleme yöntemi, literatürde sıklıkla tercih edilen yarık ekleme yöntemine göre daha kolay bir tasarıma sahiptir. Çünkü bir doğru boyunca uzanan şeritten meydana gelir ve farklı varyasyonlara sahip yarıklar gibi komplike bir yapıda değildir. $\mathrm{Bu}$ durum antenin tasarım aşamasında avantaj sağlamaktadır.

\subsubsection{EBB Yaptsı Kullanma}

Son yıllarda yapılan çalışmalarda, UGB antende bant çentik karakteristiği elde etmek için geliştirilen yeni bir teknik de EBB tekniğidir. EBB, metalik bir parçadan meydana gelir ve toprak düzlemi ile yama düzlemi arasında bağlantı kurulmasını sağlayan kısa bir pin görevi görür.

Mohammad Yazdi ve ark. mantar şekline benzer EBB yapısı kullanarak WLAN frekans bandında, bant çentik karakteristiği gösteren UGB anten tasarlamıştır. Antende alt katman malzemesi olarak RT/Duroid 4003, besleme yöntemi olarak da mikroşerit hat beslemesi tercih edilmiştir. EBB yapısı besleme hattı etrafına konumlandırılarak LC filtre devresi gibi davranması sağlanmış ve WLAN bandında bant çentik karakteristiği gösteren bir mikroşerit anten elde edilmiştir. Elde edilen anten; 35 x $39 \mathrm{~mm}^{2}$ boyuta sahiptir (Mohammad Yazdi ve ark., 2011).

Lin Peng ve ark. konik şekilli yama altında üç adet EBB yapısı kullanarak sırasıyla, WiMAX ve WLAN (3.4, 5.2, 5.8$\mathrm{GHz}$ ) frekans bantlarında, bant çentik karakteristiği gösteren UGB anten tasarlamıştır. Antende alt katman malzemesi olarak Rogers RO4003C, besleme yöntemi olarak da mikroşerit hat beslemesi tercih edilmiştir. Elde edilen anten; $22 \times 32 \mathrm{~mm}^{2}$ boyuta ve 2 ile $5.7 \mathrm{dBi}$ aras1 kazanca sahiptir (Lin Peng ve ark., 2013).

Sumon Modak ve ark. spiral şekilli EBB ve çatal şekilli yarık kullanarak C-bant (4 ve $6.5 \mathrm{GHz}$ ), X-bant LTE ve WLAN frekans 
bantlarında, bant çentik karakteristiği gösteren UGB anten tasarlamıştır. Antende alt katman malzemesi olarak FR-4, besleme yöntemi olarak da mikroşerit hat beslemesi tercih edilmiştir. Besleme hattı etrafına EBB şekillerinin konumlandırılmasıyla iki bandın, dikdörtgensel yama içerisinde yarık kullanılmasıyla da diğer üç bandın filtrelenmesi sağlanmıştır. Elde edilen anten; 31.3 x $34.9 \mathrm{~mm}^{2}$ boyuta ve 2.9 ile $10.5 \mathrm{GHz}$ arası çalışma frekansına sahiptir (Sumon Modak ve ark., 2020).

Örnek bir EBB yapısı Şekil 2'de gösterildiği gibidir.

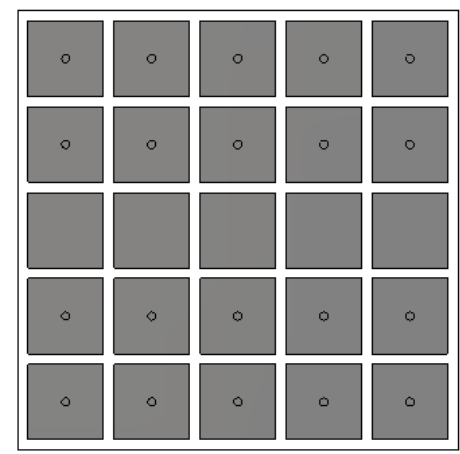

Şekil 2. Örnek Bir EBB Yapısı

\subsubsection{YHR Yapısı Kullanma}

Bant çentik uygulamalarında kullanılan diğer bir teknik de anten tasarımında YHR veya Tamamlayıcı Yarı Halka Rezonatörü (TYHR) tercih edilmesidir. Bu yapıya da örnek olarak dikdörtgensel bir yama üzerine TYHR ve alt katman üzerine YHR eklenmesiyle oluşturulan anten geometrisi Şekil 3'de gösterilmiştir. Bir YHR, dikdörtgensel veya dairesel yapıda olan, birbirine zit bir çift halkadan meydana gelir. Yapılan çalışmalardan elde edilen bulgulara göre YHR boyutlarında yapılan değişiklikler ile farklı frekans bantlarında bant çentik karakteristiği elde etmek mümkündür.

J. Liu ve ark. dairesel yama içerisine TYHR ekleme yöntemi ile WiMAX ve WLAN frekans frekans bantlarında, bant çentik karakteristiği gösteren UGB anten tasarlamıștır. Antende besleme yöntemi olarak da mikroşerit hat beslemesi tercih edilmiştir. Ayrıca yazarlar, TYHR'nin iç ve dış halkasının genişliği değiştirilerek farklı frekans bantlarında durdurma sağlanabileceğini vurgulamışlardır. Elde edilen anten; 40.9 × 34 $\mathrm{mm}^{2}$ boyuta ve 2.9 ile $12 \mathrm{GHz}$ arası çalışma frekansına sahiptir (J. Liu ve ark., 2008).

Debdeep Sarkar ve ark. eliptik TYHR ve dikdörtgensel TYHR kullanarak WiMAX, WLAN ve X-bant frekans bantlarında, bant çentik karakteristiği gösteren UGB anten tasarlamıştır. Antende alt katman malzemesi olarak FR-4, besleme yöntemi olarak da mikroşerit hat beslemesi tercih edilmiştir. Antende eliptik TYHR ile WiMAX ve WLAN bandını, dikdörtgensel TYHR ise X bandını filtrelemektedir. Elde edilen anten; 35 x $35 \mathrm{~mm}^{2}$ boyuta ve 2.21 ile $11.71 \mathrm{GHz}$ arası çalışma frekansına sahiptir (Debdeep Sarkar ve ark., 2014).

Jyotshna ve ark. yama düzlemine TYHR ekleme yöntemi ile WiMAX ve WLAN frekans bantlarında, bant çentik karakteristiği gösteren UGB anten tasarlamıştır. Antende alt katman malzemesi olarak FR-4, besleme yöntemi olarak da mikroşerit hat beslemesi tercih edilmiştir. Elde edilen anten; 26 x $30 \mathrm{~mm}$ boyuta ve 3 ile 11 $\mathrm{GHz}$ arası çalışma frekansına sahiptir (Jyotshna ve ark., 2015). Ayrica tasarlanan antenin, istenen frekans bandinda filtreleme sağlaması için kullanılacak YHR'nin eşdeğer uzunluğu aşağıdaki formülde gösterildiği gibi hesaplanmaktadır:

$$
\begin{gathered}
L_{e q}=2 *\left(L_{m}+L_{n}\right)-G_{i}-4 W_{i} \\
f_{r}=\frac{C}{2 * L e q * \sqrt{\frac{\varepsilon_{r}+1}{2}}}
\end{gathered}
$$

burada, $f_{r}$, durdurulacak bandin rezonans frekansını; Leq, rezonatörün eşdeğer uzunluğunu; $\varepsilon_{r}$, alt katmanın dielektrik sabitini; $C$, ışık hızını $\left(3 \times 10^{8} \mathrm{~m} / \mathrm{s}\right) ; L_{m}$ ve $L_{n}$, rezonatörün uzunluklarını; $G_{i}$, rezonatörün açıklığını; $W_{i}$, rezonatörün genişliğini temsil etmektedir.

A. Naghar ve ark. anten tasarımında YHR kullanarak WLAN ve X-bant frekans bantlarında, bant çentik karakteristiği gösteren UGB anten tasarlamıştır. Antende alt katman malzemesi olarak Rogers ULTRALAM 2000, besleme yöntemi olarak da mikroşerit hat beslemesi tercih edilmiştir. Yazarlar, toprak düzlemine yerleştirilen parazitik YHR ile WLAN bandını, yama düzlemine yerleştirilen dikdörtgensel şekilli YHR ile X-bant frekans bandının reddedilmesini sağlamıştır. Elde edilen anten; 30 x 35 $\mathrm{mm}^{2}$ boyuta ve 2.8 ile $12 \mathrm{GHz}$ arası çalışma frekansına sahiptir (A. Naghar ve ark., 2016).

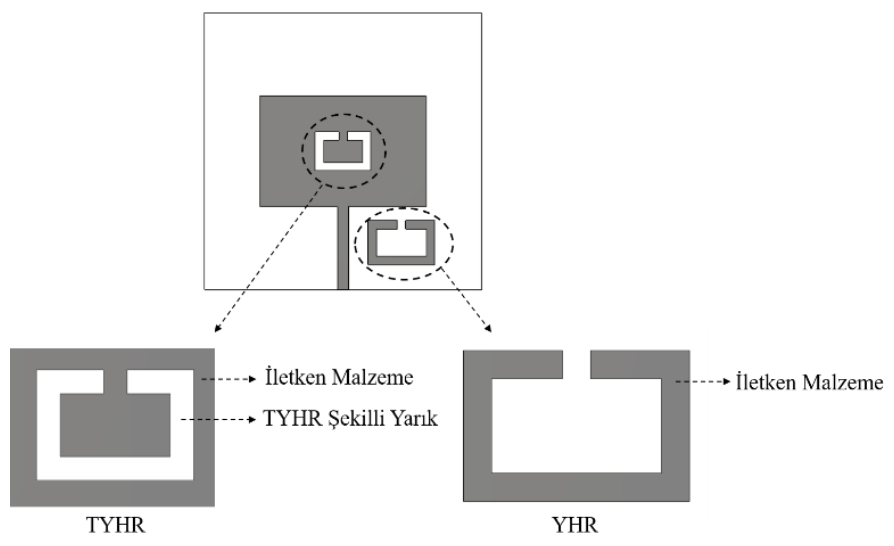

Şekil 3. TYHR ve YHR Yapısı Kullanılarak Oluşturulan Anten
Geometrisi

Lin-Chuan Tsai ve ark. TYHR tasarımına sahip, WiMAX ve WLAN frekans bantlarında, bant çentik karakteristiği gösteren UGB anten tasarlamıştır. Antende alt katman malzemesi olarak FR-4, besleme yöntemi olarak da düzlemsel dalga kılavuzu besleme yöntemi tercih edilmiştir. Anten tasarımında iki adet YHR toprak düzlemine konumlandırılarak bant çentik karakteristiği elde edilmiştir. Tasarlanan anten; 78 x $44.6 \mathrm{~mm}^{2}$ boyuta, 2.44 ile $10.79 \mathrm{GHz}$ arası çalışma frekansına ve $3.6 \mathrm{dBi}$ gibi maksimum kazanca sahiptir (Lin-Chuan Tsai ve ark., 2016).

Wei Xiao ve ark. yama düzleminde eliptik şekilli TYHR kullanarak WiMAX ve WLAN frekans bantlarında, bant çentik karakteristiği gösteren UGB anten tasarlamıştır. Antende alt katman malzemesi olarak ultra likit kristal polimer, besleme yöntemi olarak da mikroşerit hat beslemesi tercih edilmiştir. Yama düzleminde kullanılan ve üç katmandan oluşan eliptik TYHR'nin; dış katmanı WiMAX, orta katmanı WLAN (5.15-5.35 GHz), iç katmanı da WLAN (5.725-5.825 GHz) bandinda filtreleme sağlamıştır. Elde edilen anten; 27 x $21 \mathrm{~mm}^{2}$ boyuta ve $2.41 \mathrm{dBi}$ kazanca sahiptir (Wei Xiao ve ark., 2016). 
Ajay Yadav ve ark. TYHR ve S şekilli yarık kullanarak WiMAX, WLAN ve X-bant frekans bantlarında, bant çentik karakteristiği gösteren UGB anten tasarlamıştır. Antende alt katman malzemesi olarak FR-4, besleme yöntemi olarak da mikroşerit hat beslemesi tercih edilmiştir. Yazarlar anten tasarımında YHR kullanarak X-bant; TYHR ve S şekilli yarık kullanarak da WiMAX ve WLAN bantlarında bant çentik karakteristiği elde etmişlerdir. Elde edilen anten; 26 x $30 \mathrm{~mm}^{2}$ boyuta, 3 ile $11 \mathrm{GHz}$ arası çalışma frekansına ve $5 \mathrm{dBi}$ kazanca sahiptir (Ajay Yadav ve ark., 2017).

Latheef A. Shaik ve ark. YHR'nin, anten üzerinde farklı noktalara yerleştirilmesiyle $6.6 \mathrm{GHz}$ ve $7.49 \mathrm{GHz}$ merkez frekans bantlarında, bant çentik karakteristiği gösteren UGB anten tasarlamıştır. Antende alt katman malzemesi olarak RT duroid, besleme yöntemi olarak da düzlemsel dalga kılavuzu besleme metodu tercih edilmiştir. Tasarlanan antende, aynı karakteristik özelliklere sahip iki katmanlı alt katman tercih edilmiş ve YHR'nin, bu alt katmanın farklı noktalarına yerleştirilmesiyle bant çentik özelliği elde edilmiştir. Elde edilen anten; 50 x $50 \mathrm{~mm}^{2}$ boyuta, 2 ile $12 \mathrm{GHz}$ arası çalışma frekansına ve 1 ile $3 \mathrm{dBi}$ arası kazanca sahiptir (Latheef A. Shaik ve ark., 2018).

Ajay Yadav ve ark. TYHR ve U şekilli yarık kullanarak WiMAX, WLAN ve C-bant frekans bantlarında, bant çentik karakteristiği gösteren UGB anten tasarlamıştır. Antende alt katman malzemesi olarak FR-4, besleme yöntemi olarak da düzlemsel dalga kılavuzu beslemesi tercih edilmiştir. Yazarlar anten tasarımında, yama düzlemine yerleştirilen TYHR ile WiMAX ve WLAN bantlarında, U şekillli yarık ile de C-bandında filtreleme sağlamışlardır. Elde edilen anten; 26 x $30 \mathrm{~mm}^{2}$ boyuta ve 3 ile $11 \mathrm{GHz}$ arası çalışma frekansına sahiptir (Ajay Yadav ve ark., 2019).

Zaid A. Abdul Hassain ve ark. YHR'nin, anten üzerinde farklı noktalara yerleştirilmesiyle WLAN (5.15-5.35 ve 5.725-5.85 $\mathrm{GHz}$ ) ve X-bant frekans bantlarında, bant çentik karakteristiği gösteren UGB anten tasarlamıştır. Antende alt katman malzemesi olarak FR-4, besleme yöntemi olarak da mikroşerit hat beslemesi tercih edilmiştir. Yazarlar tasarladıkları UGB antenin, WLAN bandında bant çentik karakteristiği göstermesi için besleme hattı yanına 4 adet YHR konumlandırmışlardır. X bandı reddi için de toprak düzleminde üç farklı boyuta sahip TYHR oluşturulmuştur. Elde edilen anten, $30 \times 35 \mathrm{~mm}^{2}$ boyuta ve $6.6 \mathrm{~dB}$ kazanca da sahiptir (Zaid A. Abdul Hassain ve ark., 2019).

YHR ve TYHR kullanılarak yapılan çalışmalarda; boyut, frekans bant genişliği ve kazanç anlamında daha iyi sonuçlar elde edildiği görülmüştür. Bunun sebebi de rezonatörlerin bir elektromanyetik metamalzeme elemanı olması ve böylece antenin elektromanyetik alanda sıradışı özellikler göstermesi sayesinde olduğu düşünülmektedir.

\subsubsection{Hibrit Teknik Kullanma}

Bazı araştırmacılar bant çentik karakteristiği elde etmek için; yarık, saplama, parazitik şerit vb. gibi birden fazla tekniği birlikte uygulamış ve buna da hibrit teknik ismi vermişlerdir.
Shobhit Saxena ve ark. yarık ve spiral şekilli saplama kullanarak hibrit bir teknik ile yedi adet frekans bandında, bant çentik karakteristiği gösteren UGB anten tasarlamıştır. Antende alt katman malzemesi olarak FR-4 tercih edilmiştir ve bu çalışmada Anten-1 ve Anten-2 adı verilen iki adet anten tasarlanmıştır. Anten-1'de geniş altıgen yarık, altıgen ve dikdörtgensel saplama kullanılarak UGB bandında çalışan, dairesel polarize anten elde edilmiştir. Anten-2'de ise dikdörtgensel spiral şekli kullanılarak bant çentik karakteristiği gösteren bir yapı tasarlanmıştır. Elde edilen anten; $25 \times 25 \mathrm{~mm}^{2}$ boyuta, 3.1 ile $10.8 \mathrm{GHz}$ arası çalışma frekansına, $6.6 \mathrm{~dB}$ kazanca ve eksenel oranın 3'ün altında olduğu $4.1 \mathrm{GHz}$ bant genişliğine sahiptir (Shobhit Saxena ve ark., 2018).

Zhijun Tang ve ark. dört çift eleman kullanarak gerçekleştirdikleri Çoklu Giriş-Çoklu Çıkış (ÇGÇÇ) anten tasarım yöntemiyle WiMAX, WLAN ve X-bant frekans bantlarında, bant çentik karakteristiği gösteren UGB anten tasarlamıştır. Antende alt katman malzemesi olarak FR-4, besleme yöntemi olarak da mikroşerit hat beslemesi tercih edilmiştir. Yazarlar, gerçekleştirdikleri ÇGÇÇ anten tasarımında, $\mathrm{H}$ ve $\mathrm{L}$ şekilli yarıklar kullanarak WLAN bandında, U ve $\mathrm{L}$ şekilli yarıklar kullanarak da WiMAX ve X-bant frekans bantlarında bant çentik karakteristiği elde etmişlerdir. Ayrıca tasarımda kullanılan simetrik ortogonal yapılar ve merdiven şekilli yarıklar da ÇGÇÇ antenin karşılıklı bağlantısını engellemiştir. Elde edilen anten; 39 x $39 \mathrm{~mm}^{2}$ boyuta, 2.3 ile $13.75 \mathrm{GHz}$ arası çalışma frekansına ve $1.40 \mathrm{dBi}$ ile $4.60 \mathrm{dBi}$ arası kazanca sahiptir (Zhijun Tang ve ark., 2019).

Vutukuri Sarvani Duti Rekha ve ark. ÇGÇÇ anten tasarımına yarık ekleme yöntemi ile WiMAX ve askeri radar uygulamalarını içeren frekans bantlarında, bant çentik karakteristiği gösteren UGB anten tasarlamıştır. Antende alt katman malzemesi olarak FR-4, besleme yöntemi olarak da düzlemsel dalga k1lavuzu besleme yöntemi tercih edilmiştir. ÇGÇÇ anten tasarımında bir çift eleman kullanarak UGB bandında çalışan, daha sonra da iki çift eleman kullanarak bant çentik karakteristiği gösteren anten elde etmiştir. Elde edilen anten; $80 \times 80 \mathrm{~mm}^{2}$ boyuta, 2.1 ile 20 $\mathrm{GHz}$ arası çalışma frekansına ve $5.8 \mathrm{dBi}$ maksimum kazanca sahiptir (Vutukuri Sarvani Duti Rekha ve ark., 2020).

\section{Araştırma Sonuçları ve Tartışma}

Bant çentik uygulamaları için yapılan araştırmalardan elde edilen bulgular Tablo 1'de özetlenmektedir. Bu tabloya göre, literatürde yapılan çalışmaların büyük çoğunluğunun WiMAX, WLAN, C-bant ve X-bant frekans bantlarında bant çentik karakteristiği gösterdiği gözlenmektedir. Tasarlanan yapılardan boyut olarak en küçüğünün $294 \mathrm{~mm}^{2}$, en büyüğünün ise 6400 $\mathrm{mm}^{2}$ boyuta sahip olduğu görülmektedir. Literatürdeki yapılar incelendiğinde frekans bant genişliğinin en geniş bantlı tasarımda $18 \mathrm{GHz}$ (boyutu $80 \times 80 \mathrm{~mm}^{2}$ ), en dar bant genişliğine sahip tasarımda $7.9 \mathrm{GHz}$ (boyutu $28 \times 30 \mathrm{~mm}^{2}$ ) olduğu gözlenmektedir. Ayrıca tasarlanmış yapıların çoğunda Rogers ve FR-4 alt katmanlarının tercih edildiği görülmektedir. 
Tablo 1. Literatürde Yapılmış Çalışmaların Karşılaştırma Tablosu

\begin{tabular}{|c|c|c|c|c|c|c|}
\hline Kaynak & $\begin{array}{l}\text { Kullanılan } \\
\text { Yöntem }\end{array}$ & $\begin{array}{l}\text { Boyut } \\
\left(\mathbf{m m}^{2}\right)\end{array}$ & $\begin{array}{l}\text { Dielektrik } \\
\text { Sabiti }\end{array}$ & $\begin{array}{l}\text { Bant Çentik Karakteristiği } \\
\text { Gösteren Frekans Bandı }\end{array}$ & $\begin{array}{c}\text { Kazanç } \\
\text { (dBi) }\end{array}$ & $\begin{array}{c}\text { Frekans } \\
\text { Bant } \\
\text { Aralığı } \\
\text { (GHz) }\end{array}$ \\
\hline $\begin{array}{l}\text { Husham J. Mohammed } \\
\text { ve ark., } 2016\end{array}$ & $\begin{array}{c}\text { Yarık } \\
\text { Kullanma }\end{array}$ & $28 \times 30$ & 4,4 & WiMAX, WLAN, C-bant & N/A & $2.7-10.6$ \\
\hline $\begin{array}{c}\text { Neelaveni Ammal } \\
\text { Murugan ve ark., } 2016 \\
\end{array}$ & $\begin{array}{c}\text { Yarık } \\
\text { Kullanma } \\
\end{array}$ & $30 \times 28$ & 4,4 & WiMAX, WLAN, X-bant & 4.67 & N/A \\
\hline $\begin{array}{c}\text { Hari Shankar Mewara } \\
\text { ve ark., } 2017\end{array}$ & $\begin{array}{c}\text { Yarık } \\
\text { Kullanma }\end{array}$ & $36 \times 38$ & 4,4 & $\begin{array}{c}\text { WiMAX, WLAN, X-bant, ITU-8, } \\
\text { RN }\end{array}$ & 4.5 & $2.86-13.3$ \\
\hline $\begin{array}{l}\text { H. Hosseini ve ark., } \\
2018\end{array}$ & $\begin{array}{c}\text { Yarık } \\
\text { Kullanma }\end{array}$ & $21 \times 14$ & 3,55 & WiMAX, WLAN, X-bant & 2.3 & $3.0-12.0$ \\
\hline $\begin{array}{l}\text { Junhui Wang ve ark., } \\
2013\end{array}$ & $\begin{array}{c}\text { Saplama } \\
\text { Modülü } \\
\text { Kullanma }\end{array}$ & $26 \times 27.3$ & 4,4 & WIMAX, WLAN & N/A & $3.0-11.0$ \\
\hline $\begin{array}{l}\text { Xianglong Liu ve ark., } \\
2013\end{array}$ & $\begin{array}{l}\text { Parazitik } \\
\text { Serit } \\
\text { Kullanma }\end{array}$ & $40 \times 30$ & 4,4 & WIMAX, WLAN & 7.3 & N/A \\
\hline Ke Zhang ve ark., 2010 & $\begin{array}{c}\text { Parazitik } \\
\text { Serit } \\
\text { Kullanma } \\
\end{array}$ & $37 \times 47$ & 3 & WLAN & N/A & $2.8-13.5$ \\
\hline Lin Peng ve ark., 2013 & $\begin{array}{l}\text { EBB Yap1s1 } \\
\text { Kullanma }\end{array}$ & $22 \times 32$ & 3,38 & WiMAX, WLAN & N/A & N/A \\
\hline $\begin{array}{c}\text { Sumon Modak ve ark., } \\
2020\end{array}$ & $\begin{array}{l}\text { EBB Yap1s1 } \\
\text { Kullanma }\end{array}$ & $\begin{array}{c}31.3 \mathrm{x} \\
34.9 \\
\end{array}$ & 4,4 & C-bant, X-bant, LTE, WLAN & N/A & $2.9-10.5$ \\
\hline $\begin{array}{l}\text { Latheef A. Shaik ve ark., } \\
2018\end{array}$ & $\begin{array}{l}\text { YHR Yaps1 } \\
\text { Kullanma }\end{array}$ & $50 \times 50$ & 2,33 & $6.6 \mathrm{GHz}$ ve $7.49 \mathrm{GHz}$ & $1-3$ & $2-12$ \\
\hline $\begin{array}{l}\text { Ajay Yadav ve ark., } \\
2019\end{array}$ & $\begin{array}{l}\text { YHR Yaps1 } \\
\text { Kullanma }\end{array}$ & $26 \times 30$ & 4,4 & WiMAX, WLAN, C-bant & N/A & $3-11$ \\
\hline $\begin{array}{l}\text { Zhijun Tang ve ark., } \\
2019\end{array}$ & $\begin{array}{c}\text { Hibrit } \\
\text { Teknik } \\
\text { Kullanma } \\
\end{array}$ & $39 \times 39$ & 4,4 & WiMAX, WLAN, X-bant & 4.60 & $2.3-13.75$ \\
\hline $\begin{array}{l}\text { Vutukuri Sarvani Duti } \\
\text { Rekha ve ark., } 2020\end{array}$ & $\begin{array}{c}\text { Hibrit } \\
\text { Teknik } \\
\text { Kullanma }\end{array}$ & $80 \times 80$ & 4,4 & $\begin{array}{l}\text { WiMAX, askeri radar } \\
\text { uygulamaları }\end{array}$ & 5.8 & $2.1-20$ \\
\hline
\end{tabular}

\section{Sonuç}

$\mathrm{Bu}$ çalışma kapsamında, UGB (3.1-10.6 GHz) frekans bandında çalışan ve WiMAX (3.3-3.7 GHz), WLAN (5.15-5.85 $\mathrm{GHz}), \mathrm{C}$-bant (3.8-4.2 GHz), X-bant (7.25-7.75 GHz) gibi dar bant genişliğine sahip frekans bantlarında bant çentik karakteristiği gösteren mikroşerit anten çalışmalarının derlemesi sunulmuştur. Literatürdeki çalışmalar incelendiğinde, tasarlanan UGB antenlerinin bant çentik karakteristiği göstermesi için yama ve toprak düzleminde yarıklar kullanma, besleme hattı veya toprak düzleminde saplamalar kullanma, parazitik şerit kullanma, EBB yapıları kullanma ve YHR kullanma gibi birçok farklı teknikten yararlanıldığg görülmüştür. Bu tekniklerden, yama ve toprak düzleminde yarıklar oluşturulması en basit ve alışagelmiş̧ olanıdır ve bu yöntemin pek çok araştırmacı tarafından sıklıkla tercih edildiği görülmektedir. Anten tasarımında yarık kullanmanın yanı sıra YHR kullanılarak oluşturulan yapılarda anten boyutu ve frekans bant genişliğinde iyileştirme sağlandığı görülmüştür. Yapılan derleme çalışması sonucunda, bant çentik karakteristiği gösteren mikroşerit antenlerin tasarımı ile UGB iletişiminde parazitlenmelerin önüne geçilerek iletişim kalitesinin arttırıldığı sonucuna varılmıştır.

\section{Kaynakça}

Balanis, C. A. (2016). Antenna theory: analysis and design. John wiley \& sons.

FC Commission. (2002). Revision of part 15 of the commission's rules regarding ultra-wideband transmission systems. First report and order, 02-48.

Oppermann, I., Hämäläinen, M., \& Iinatti, J. (Eds.). (2005). UWB: theory and applications. John Wiley \& Sons.

Mohammed, H. J., Abdullah, A. S., Ali, R. S., Abd-Alhameed, R. A., Abdulraheem, Y. I., \& Noras, J. M. (2016). Design of a uniplanar printed triple band-rejected ultra-wideband antenna using particle swarm optimisation and the firefly algorithm. IET Microwaves, Antennas \& Propagation, 10(1), 31-37.

Murugan, N. A., Balasubramanian, R., \& Patnam, H. R. (2016). Printed ultra-wideband monopole U-slotted antenna for triple band-rejection. Journal of ElEctromagnEtic WavEs and applications, 30(12), 1532-1544.

Mewara, H. S., Deegwal, J. K., \& Sharma, M. M. (2018). A slot resonators based quintuple band-notched Y-shaped planar monopole ultra-wideband antenna. AEU-International Journal of Electronics and Communications, 83, 470-478. 
Hosseini, H., Hassani, H. R., \& Amini, M. H. (2018). Miniaturised multiple notched omnidirectional UWB monopole antenna. Electronics Letters, 54(8), 472-474.

Jiang, W., \& Che, W. (2012). A novel UWB antenna with dual notched bands for WiMAX and WLAN applications. IEEE Antennas and Wireless Propagation Letters, 11, 293-296.

Wang, J., Yin, Y., Liu, X., \& Wang, T. (2013). Trapezoid UWB antenna with dual band-notched characteristics for WiMAX/WLAN bands. Electronics Letters, 49(11), 685-686.

Liu, X. L., Yin, Y. Z., Liu, P. A., Wang, J. H., \& Xu, B. (2013). A CPW-fed dual band-notched UWB antenna with a pair of bended dual-L-shape parasitic branches. Progress In Electromagnetics Research, 136, 623-634.

Zhang, K., Li, Y., \& Long, Y. (2010). Band-notched UWB printed monopole antenna with a novel segmented circular patch. IEEE Antennas and Wireless Propagation Letters, 9, 1209. 1212.

Yazdi, M., \& Komjani, N. (2011). Design of a band-notched UWB monopole antenna by means of an EBG structure. IEEE Antennas and Wireless Propagation Letters, 10, 170-173.

Peng, L., \& Ruan, C. L. (2013). Design and time-domain analysis of compact multi-band-notched UWB antennas with EBG structures. Progress In Electromagnetics Research, 47, 339357.

Modak, S., Khan, T., \& Laskar, R. H. (2020). Penta-notched UWB monopole antenna using EBG structures and fork-shaped slots. Radio Science, 55(9), 1-11.

Liu, J., Gong, S., Xu, Y., Zhang, X., Feng, C., \& Qi, N. (2008). Compact printed ultra-wideband monopole antenna with dual band-notched characteristics. Electronics letters, 44(12), 710711.

Sarkar, D., Srivastava, K. V., \& Saurav, K. (2014). A compact microstrip-fed triple band-notched UWB monopole antenna. IEEE Antennas and Wireless Propagation Letters, 13, 396399.

Jyotshna, J. P. SRR Loaded Dual Band Notched Ultra Wideband Microstrip Antenna.

Naghar, A., Falcone, F., Alejos, A., Aghzout, O., \& Alvarez, D. (2016). A Simple UWB Tapered Monopole Antenna with Dual Wideband-Notched Performance by Using Single SRR-Slot and Single SRR-Shaped Conductor-Backed Plane. Applied Computational Electromagnetics Society Journal, 31(9).

Tsai, L. C., \& Chen, W. J. (2016). A UWB antenna with bandnotched filters using slot-type split ring resonators. Microwave and Optical Technology Letters, 58(11), 25952598.

Xiao, W., Mei, T., Lan, Y., Wu, Y., Xu, R., \& Xu, Y. (2016). Triple band-notched UWB monopole antenna on ultra-thin liquid crystal polymer based on ESCSRR. Electronics Letters, 53(2), 57-58.

Yadav, A., Agrawal, S., \& Yadav, R. P. (2017). SRR and S-shape slot loaded triple band notched UWB antenna. AEUInternational Journal of Electronics and Communications, 79, 192-198.

Shaik, L. A., Saha, C., Antar, Y. M., \& Siddiqui, J. Y. (2018). An antenna advance for cognitive radio: Introducing a multilayered split ring resonator-loaded printed ultrawideband antenna with multifunctional characteristics. IEEE Antennas and Propagation Magazine, 60(2), 20-33.

Yadav, A., Sharma, M. D., \& Yadav, R. P. (2019). A CPW-fed CSRR and inverted U slot loaded triple band notched UWB antenna. Progress In Electromagnetics Research, 89, 221-231.
Hassain, Z. A. A., Ali, M. M., \& AZEE, A. (2019). Single and Dual Band-Notch UWB Antenna Using SRR/CSRR Resonator. Journal of Communications, 14(6), 504-510.

Saxena, S., Kanaujia, B. K., Dwari, S., Kumar, S., \& Tiwari, R. (2018). Compact ultra-wideband microstrip antenna with dual polarisation/multi-notch characteristics. IET Microwaves, Antennas \& Propagation, 12(9), 1546-1553.

Tang, Z., Wu, X., Zhan, J., Hu, S., Xi, Z., \& Liu, Y. (2019). Compact UWB-MIMO antenna with high isolation and triple band-notched characteristics. IEEE Access, 7, 19856-19865.

Rekha, V. S. D., Pardhasaradhi, P., Madhav, B. T. P., \& Devi, Y. U. (2020). Dual Band Notched Orthogonal 4-Element MIMO Antenna With Isolation for UWB Applications. IEEE Access, $8,145871-145880$. 